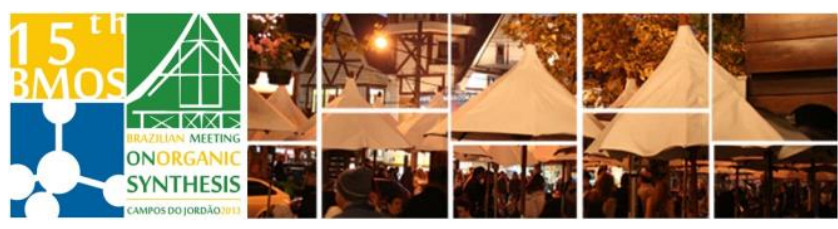

\title{
Coibacins A and B: Total Synthesis, Stereochemical Revision and Structural Elucidation
}

\section{Carolina M. Avila, ${ }^{a}$ Vânia M. T. Carneiro, ${ }^{a}$ Marcy J. Balunas, ${ }^{b}$ William H. Gerwick, ${ }^{b}$ Ronaldo A. Pilli*,a}

a Institute of Chemistry, University of Campinas, UNICAMP, Campinas, SP, Brazil. b Department of Pharmaceutical Sciences, University of Connecticut, Storrs, CT, USA. ' Scripps Institution of Oceanography, University of California San Diego, La Jolla, CA, USA. *pill@iqm.unicamp.br

Keywords: Coibacins, Total Synthesis, Structural Elucidation.

\section{INTRODUCTION}

Coibacins A (1) and B (2) are polyketides isolated from a Panamanian marine cyanobacterium Oscillatoria sp. that display antileishmanial activity. The absolute configuration of the dihydropyran-2one moiety (C-5) was assigned to be $S$, based on circular dichroism (CD), while only the trans relative stereochemistry of the cyclopropyl ring was determined by NMR. ${ }^{1}$ We embarked on the total synthesis of stereoisomers of coibacin A (1) aiming to establish its absolute configuration. Additionally, we have synthesized the natural isomer of coibacin B (2).

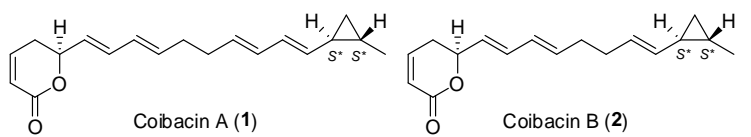

RESULTS AND DISCUSSION

We envisioned a convergent strategy via coupling of three key fragments $(\mathbf{3}, \mathbf{4} \text { and } \mathbf{6})^{2,3}$ to quickly provide two possible isomers of coibacin $A$ (1): (5S,16S,18S)- and (5S,16R,18R)-1 (Scheme 1). These synthetic compounds displayed identical ${ }^{1} \mathrm{H}$ and ${ }^{13} \mathrm{C}$-NMR data to those reported for the natural coibacin A (1). However, synthetic samples were levorotatory while the natural product is known to be dextrorotatory.

Scheme 1. Synthesis of $(5 S, 16 S, 18 S)$ - and $(5 S, 16 R, 18 R)-1$.

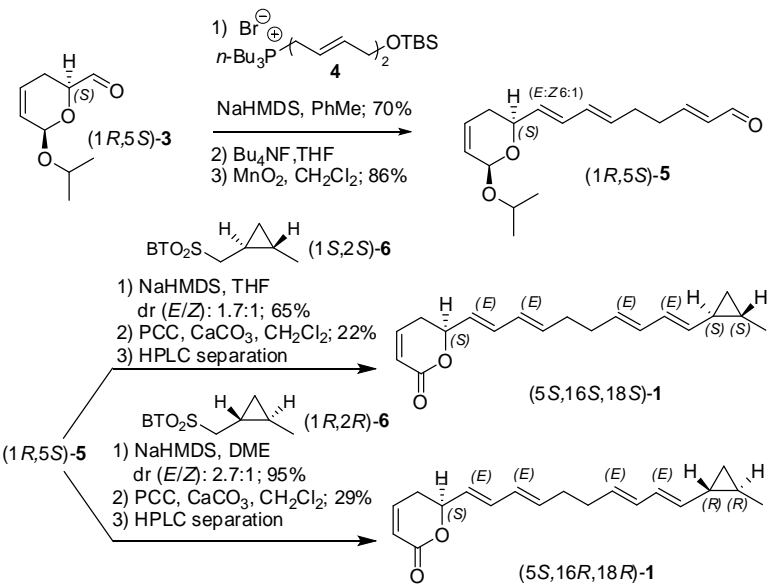

Consequently, we conducted the total synthesis of two additional isomers $(5 R, 16 S, 18 S)$ - and
$(5 R, 16 R, 18 R)-1$ (Figure 1) based on the route described above. Despite their dextrorotatory values, the specific optical rotations were significantly different from that reported for the natural sample. Therefore, we carried out HPLC comparisons of natural coibacin A (1) with all four synthetic stereoisomers, unequivocally establishing its absolute configuration as $5 R, 16 S, 18 S$.

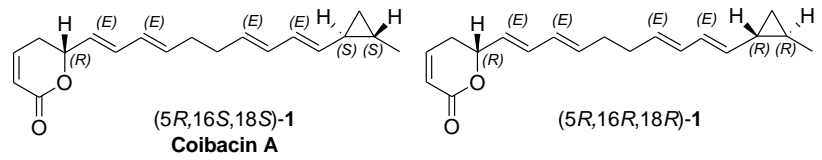

Figure 1. $(5 R, 16 S, 18 S)$ - and $(5 R, 16 R, 18 R)-1$.

A similar synthetic approach was applied to the synthesis of coibacin B (2, Scheme 2) displaying the $5 R, 14 S, 16 S$ configuration, the same one found for coibacin A (1).

Scheme 2. Synthesis of $(5 R, 14 S, 16 S)-2$.

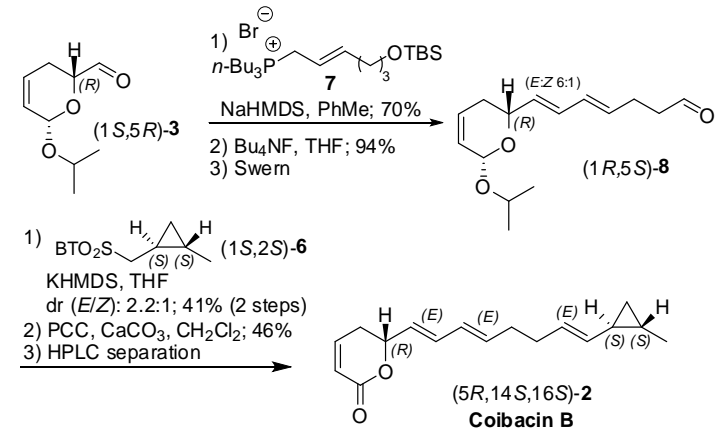

\section{CONCLUSION}

In summary, four isomers of coibacin A (1) and the correct isomer of coibacin B (2) were synthesized. We unequivocally established the absolute configuration of coibacin $\mathrm{A}(1)$ to be $5 R, 16 S, 18 S$ and the original stereochemistry at $C-5$ was corrected.

\section{ACKNOWLEDGEMENTS}

The authors would like to thank FAPESP (research Grants: $2009 / 51602-5$; $11 / 00457-5$ to VMT and 2010/08673-6 to CMA).

\section{REFERENCES}

${ }^{1}$ Balunas, M. J.; et al. Org. Lett. 2012, 14, 3878. ${ }^{2}$ Crimmins, M. T.; King, B. W. J. Am. Chem. Soc. 1998, 120, 9084. ${ }^{3}$ Charette, A. B.; Lebel, H. J. Am. Chem. Soc. 1994, 116, 2651. 